\title{
Rapid Development and Application of Prototype Test System of Prefabri- cated Metro Station Structure Joint
}

\author{
Su Huifeng ${ }^{1,2, *}$, Liu Weining ${ }^{1}$, Yang Xiuren ${ }^{3}$ and Wang Chen $^{3}$ \\ ${ }^{I}$ School of Civil Engineering, Beijing Jiaotong University, Beijing, 100044, P.R. China; ${ }^{2}$ College of Transportation, \\ Shandong University of Science and Technology, Qingdao, Shandong, 266590, P.R. China; ${ }^{3}$ Beijing Urban Construc- \\ tion Design \& Development Group Co. Limited, Beijing, 100037, P.R. China
}

\begin{abstract}
In the context of the proposed prefabricated metro station named Yuanjiadian Station for Changchun Metro Line 2 and based on the final purpose of studying the tenon and mortise grouting joint's mechanical properties, prototype test system of joint was developed and staged test finished. The test system includes loading system, test and monitoring system, assembling and grouting system, lifting and installation system and so forth. The system can complete the fourpoint bending test and four-point shearing test under any axial force of the prototype joint. Afterward, destructive test of axial force combining with bending moment was carried out under different conditions (including grouting ranges, grouting materials and tenon lengths). Ultimately, the flexural capacity and flexural rigidity for some specific tenon and mortise joint was derived and the safe bending moment of the joint was shown, providing guidance for design and construction.
\end{abstract}

Keywords: Flexural rigidity, prototype test, test system, ultimate flexural capacity.

\section{INTRODUCTION}

Recently, the proposed Yuanjiadian Station of Changchun Metro Line 2 is scheduled to take a full prefabricated structure with vertical-wall vault and column-free single arch. It will be the first total-prefabricated metro station of China. Longitudinally, seven precast blocks form one ring every two meters. One type of tenon and mortise joints with reserved space for later grouting is designed for the key circumferential and longitudinal joints. The specific form and size of the joints in different positions may be determined based on internal force, deformation and construction demand.

For the total-prefabricated structure of metro station, the most important feature is tenon and mortise grouting joints. The study of the joints' mechanical properties only by empirical model or numerical simulation does not satisfy the design requirements. The existing research of underground construction joints mostly focuses on shield segment joints, which is very different from this new one [1-8]. Given the above, joint prototype test should be conducted to study the ultimate flexural capacity, shear bearing capacity and flexural rigidity. With a view to meeting the research requirements, a feasible test system should be set up as soon as possible.

\section{DESIGN OF TEST SYSTEM}

\subsection{Test Requirements}

The test requirements are given bellow:

*Address correspondence to this author at the College of Transportation, Shandong University of Science and technology, Qingdao, Shandong, 266590, P.R. China; Tel: +18653238961; E-mail: shf7521@163.com
1. Transportation and hoisting of the test specimen should be convenient;

2. Enough loading space should be provided for the largesize specimen and the specimen should be conveniently installed, loaded and disassembled;

3. Any axial force test combining bending moment or shear force test can be conducted separately;

4. The loading process should be easily controlled. That is to say, the jacking speed and the load value should meet the requirements;

5. The test can be conveniently recorded;

6. The prototype test of single or double tenon and mortise joint can be done and there should be some space for other related tests;

7. A very real problem is that the test system must be built and put into use as soon as possible.

After the comparison of schemes, one scheme using the existing reaction wall and reaction frame system and the other scheme using long column machine can only complete partial test and the risk is high, so the above two schemes were abandoned. The scheme of building test-pit system in Changchun city east suburb's shield segment factory was adopted. It took 50 days from design to completion. The whole test system can be divided into loading system, monitoring system, assembling and grouting system, lifting and installation system.

\subsection{Loading System}

The length, width and height of test-pit is $7,200 \mathrm{~mm} \times$ $5,100 \mathrm{~mm} \times 1,500 \mathrm{~mm}$ and wall thickness $800 \mathrm{~mm}$. The pit has a built-in $\phi 25$ main reinforcement with pre-embedded $20 \mathrm{~mm}$ thick steel plates. Axial force and bending moment 


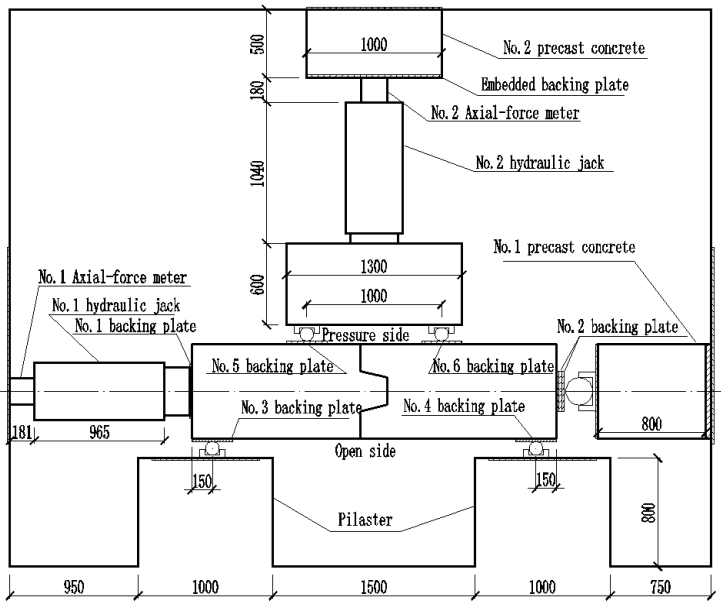

(a). Test-pit and single tenon and mortise joint loading arrangement

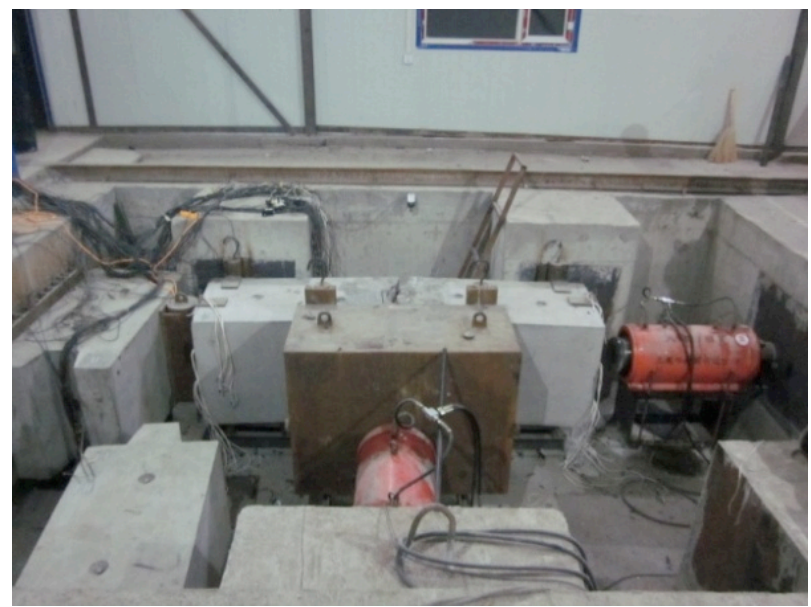

(b). Test-pit site layout

Fig. (1). Test-pit and single tenon and mortise joint test loading arrangement.

are provided by two horizontal hydraulic jacks separately. At the head of the jack, one universal joint is put to prevent the axial force from direction migration. Among the jacks, one provides bending moment to the test specimen via the distribution beam. And finally pit pilasters provide reaction. The distribution beam is made of thick steel plate with rib beam inside to offer enough stiffness. Several groups of force points are set on the beam. Vertical and axial bearings are solid steel bars with diameter of $100 \mathrm{~mm}$ and $200 \mathrm{~mm}$ respectively. The bottom of the test specimen is based with greased rollers. Between the test specimen and the bearings is a $20 \mathrm{~mm}$ thick steel plate to prevent the test specimen from local crushing. Within the expected load range, the loading system can meet the requirements of four-point bending test and four-point shearing test. The loading system is shown in Fig. (1).

\subsubsection{Jack Selection}

The hydraulic servo system does not only cost too much, but also requires long time to prepare and install. So it cannot be considered. Normally, the metro station is buried under a depth between $3 \mathrm{~m}$ to $5 \mathrm{~m}$. So, based on the load structure theory, the internal force is obtained. In the calculation, a variety of conditions such as 0 to full rigidity of the joint stiffness was considered. The result is that the axial force is between $1,500 \mathrm{kN}$ to $2,500 \mathrm{kN}$ and the largest moment of the joint is $535 \mathrm{kN}$.m. Considering the efficiency of the hydraulic jacks, two hydraulic jacks with rated tonnage $4000 \mathrm{kN}$ and large-stroke $500 \mathrm{~mm}$ were selected.

\subsubsection{Oil Pump Selection}

In order to ensure the minimum jacking speed, one highpressure fuel pump with the minimum fuel delivery of 2 $\mathrm{L} / \mathrm{min}$ is selected. And the pump is equipped with constant pressure valve and digital pressure gauge. The test shows that the minimum jacking speed can be $0.28 \mathrm{~mm} / \mathrm{s}$, which is stable at the certain fuel delivery.

\subsubsection{Force Sensor}

In order for accurate measuring and real-time recording the jacking force, a high precision axial-force meter is set at the jack tail (Brand: MTM, Type: $\mathrm{C} 1-5 \mathrm{MN}$, maximum range: $5000 \mathrm{kN})$. It can output the practical axial force in a real time manner to the recorder (Brand: MTM, Type: 2000/CK6).

\subsection{Monitor System Design}

\subsubsection{Static Strain Testing System}

The test system is full intelligent circuit of data acquisition system named DH3816N. Each system module is equipped with 60 measuring points. Test needs 3 sets of modules and one spare.

\subsubsection{Image and Video Collection System}

Two HDTV cameras are installed on the wall of the testpit and laboratory so as to globally and locally record the test process. At the same time, a digital camera is equipped to take photos whenever.

\subsection{Assembling and Grouting System}

For the tenon and mortise grouting joints, another important thing is the assembly of the tenon and mortise specimens and the juncture grouting. Necessary equipment such as manual hoist (rated $5 \mathrm{t}$ ), grouting pump (maximum pressure: $0.4 \mathrm{MPa}$ ), level bar, water-proof slab and styrofoam are adopted.

\subsection{Hoisting and Transportation System}

According to the size and weight of the specimens, the shield segment factory's forklift (rated 10t) is used for transportation and electric hoist wheel-rail gantry crane for hoisting (rated 10t, max lifting height $2.7 \mathrm{~m}$ ).

\section{SECIMENS SIZE AND MONITORING ITEM}

\subsection{Specimens Size}

In the former preliminary design, the widths of the 7 joints per ring are different. The most narrow single tenon and mortise joint is $700 \mathrm{~mm}$ wide and the widest double tenon and mortise joint is $1,420 \mathrm{~mm}$ wide. The joint prototype test should be conducted conveniently and economically. 

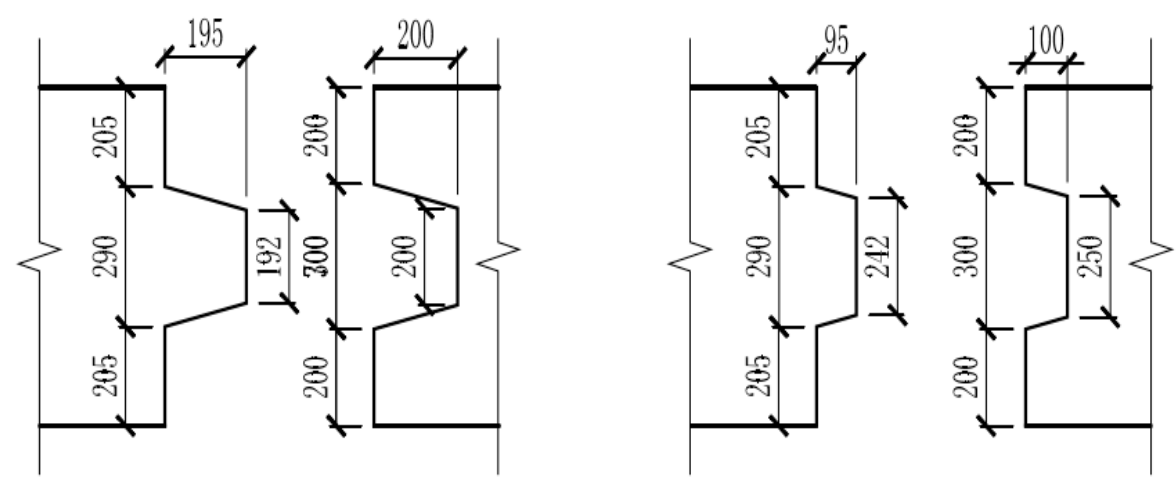

Fig. (2). Two types of single tenon and mortise specimen lengths (Unit: mm).

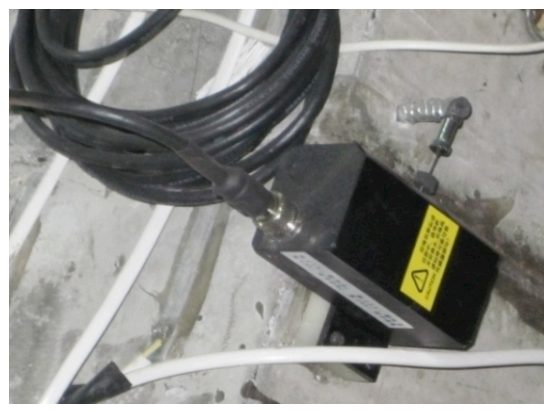

(a) Guy wire displacement sensor

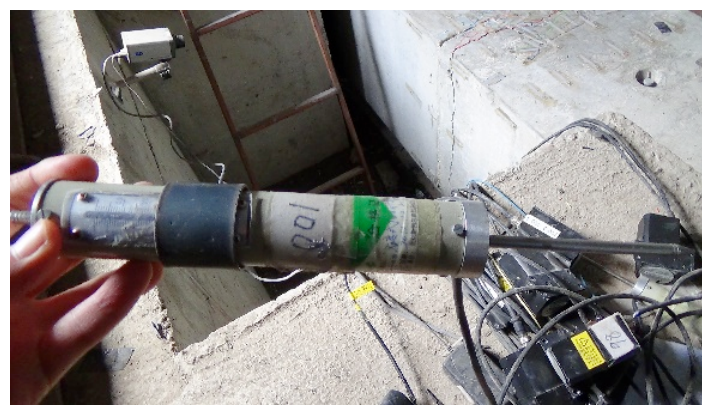

(b) Plunger displacement sensor

Fig. (3). Two types of displacement sensors.

Table 1. The number of single tenon and mortise joint specimen's strain gauges and displacement sensors.

\begin{tabular}{|c|c|c|c|c|c|}
\hline Name & \multicolumn{2}{|c|}{ Concrete Strain gauge } & \multicolumn{2}{c|}{ Steel Strain gauge } & Guy Wire (Plunger) Displacement Sensor \\
\hline \hline Tenon Length (mm) & 195 & 95 & 195 & 95 & 195,95 \\
\hline Number & 70 & 65 & 44 & 38 & $9(3)$ \\
\hline
\end{tabular}

According to the principle of Saint-Venant, except a certain range of the joint designed to the real prefabricated parts, the rest is simplified into the rectangular section. The length of the assembled single tenon and mortise joint specimen is $2,700 \mathrm{~mm}$ and the double tenon and mortise joint is 3,600 $\mathrm{mm}$ long and $500 \mathrm{~mm}$ thick.

Section size of the single tenon and mortise joint specimen is shown in Fig. (2).

\subsection{Joint Seam Opening Monitoring}

Joint seam opening is an important index of judging the waterproof effect and flexural rigidity of the joint. Two displacement sensors such as guy wire type and plunger type were used to measure the joint seam opening. According to different measurement points, the guy wire (Type: LXW-5; Linear accuracy: superior to $1 \% \mathrm{~F} . \mathrm{S}$ and resolving precision $>0.02 \mathrm{~mm}$ ) have two measuring ranges $(50 \mathrm{~mm}$ and 100 $\mathrm{mm}$ ). The plunger (Type: ZY-3770; Measuring range: $0 \mathrm{~mm}$; Linear accuracy: superior to $0.5 \% \mathrm{~F}$.S and resolving precision $>0.01 \mathrm{~mm}$ ) is convenient in measuring the joint seam opening reduction. The displacement sensors connect to the DH3816N synchronously with stress and strain and the two sensors can also check each other.
The displacement sensors are shown in Fig. (3).

\subsection{Concrete Strain and Steel Stress Monitoring}

Concrete strain and steel stress are monitored by the strain gauge. For the concrete strain monitoring, given that the small joint and its stress complexity, if the usual $100 \mathrm{~mm}$ strain gauges were used, it would be difficult to arrange the measuring points. Vice versa, if the strain were too short, the errors would be great. Based on the above reasons, the 50 $\mathrm{mm}$ concrete strain was used. For the steel strain, Type BX120-80AA was used (Table 1).

\section{TEST APPLICATION}

During the first stage, 25 single tenon and mortise specimen tests were conducted. The test involves two lengths (tenon length $195 \mathrm{~mm}$ and $95 \mathrm{~mm}$ ), three types of grouting materials (epoxy, cement-based and with no grouting), three types of grouting ranges (maximum, minimum and the designed), and five axial forces $(0,500 \mathrm{KN}, 1000 \mathrm{KN}, 1600$ $\mathrm{KN}, 2000 \mathrm{KN})$. Based on massive test data and relevant information, the single tenon and mortise joint's flexural performance was initially obtained. 

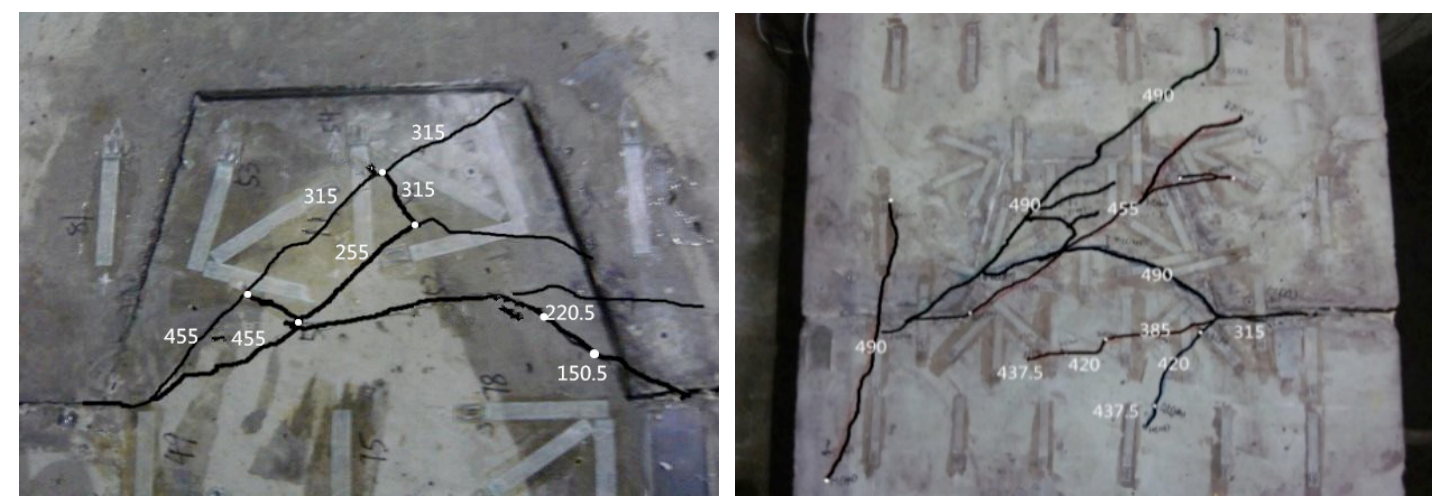

(a) Cracks developing under the condition of minimum grouting range (b) Cracks developing under the condition of designing grouting range

Fig. (4). Cracks developing under the condition of two grouting ranges.

Table 2. The key bending moment under the condition of different axial force of length $195 \mathrm{~mm}$ tenon.

\begin{tabular}{|c|c|c|c|c|c|c|}
\hline $\begin{array}{c}\text { Axial } \\
\text { Force (kN) }\end{array}$ & $\begin{array}{c}\text { Grouting } \\
\text { Range }\end{array}$ & $\begin{array}{c}\text { Cracks Appearance } \\
\text { (kN.m) }\end{array}$ & $\begin{array}{c}\text { Cracks Develop- } \\
\text { ment (kN.m) }\end{array}$ & $\begin{array}{c}\text { Cracks Cut-Through } \\
\text { the Tenon (kN.m) }\end{array}$ & $\begin{array}{c}\text { Cracks Cut-Through } \\
\text { the Structure (kN.m) }\end{array}$ & $\begin{array}{c}\text { Utimate Bending } \\
\text { Capacity (kN.m) }\end{array}$ \\
\hline \hline 0 & Minimum & 55 & $/$ & 72 & 87.5 & 108 \\
\hline 500 & Minimum & 80 & 110 & 175 & 350 & 210 \\
\hline 1000 & Minimum & 122.5 & 180 & 280 & 460 & 420 \\
\hline 1600 & Minimum & 160 & 250 & 310 & 450 \\
\hline 2000 & Minimum & 192 & 350 & 455 & 610 & 840 \\
\hline
\end{tabular}

\subsection{Study of the Joint's Ultimate Flexural Capacity}

By comparing the joint surface cracks, concrete strain, steel stress of the key position develops with the axial force and bending moment, the joint flexural capacity can be divided into several stages. Also, the safe bending moment that the joint can bear was obtained.

\subsubsection{Tenon Length $195 \mathrm{~mm}$ Specimens}

The flexural capacity of the tenon $195 \mathrm{~mm}$ can be divided into five stages: cracks appearance, cracks development, cracks cut-through the tenon, cracks cut-through the structure and losing bearing capacity, as shown in Fig. (4). The stage before cracks cut-through the tenon should be defined as the safe bearing stage.

The bending moment for different axial forces under the condition of minimum grouting range is given in Table 2 .

From Table 2, except the axial force 0 , the bending moment of cracks cut-through the structure is 2.2 times of cracks appearance stage. The bending moment of cracks appearance and the edge of specimens reaching tensile strength can be obtained by simple calculation. The other conditions of the joint are the same as described above and will not be explained here.

\subsubsection{Tenon Length $95 \mathrm{~mm}$ Specimens}

For the tenon $95 \mathrm{~mm}$ length specimens, the flexural bearing conditions are much different than the length $195 \mathrm{~mm}$. The bending stages can be divided into five stages such as stage cracks appearance, stage cracks extension to the top of the tenon, stage cracks cut-through the tenon, stage several parallel fractures appearance in groove and the final bearing stage. The stage interval after cracks appearance is too short to be distinguished (under the condition of smaller axial force), which is similar to brittle failure of the rarereinforced beam even to plain concrete beam (Fig. 5).

The key bending moment under the condition of minimum grouting range and different axial force is given in Table 3 .

For the tenon $95 \mathrm{~mm}$ length grouting joint, the bending moment of cracks appearance should be the maximum safe moment. As is known from mechanics, the bending moment is irrelevant to the reinforcement ratio but the size of the joint tenon.

\subsection{Study of the Flexural Rigidity}

According to the seam opening of joints, the flexural rigidity at different times was obtained by the method of segment tangent rigidity. The flexural rigidity test formula of the joint was found suitable. Results show that flexural rigidity and bending moment have the exponential relationship. The relationship equation is as follows:

$k_{\theta}=A e^{\frac{B-M}{A}}$

In the formula, A and B are correlation coefficients, which are related to the joint size, grouting materials, grouting range and the axial force. For the tenon $195 \mathrm{~mm}$ length specimen, the joint flexural rigidity formula under the condition of grouting epoxy and designing grouting range is given in Table 4. 


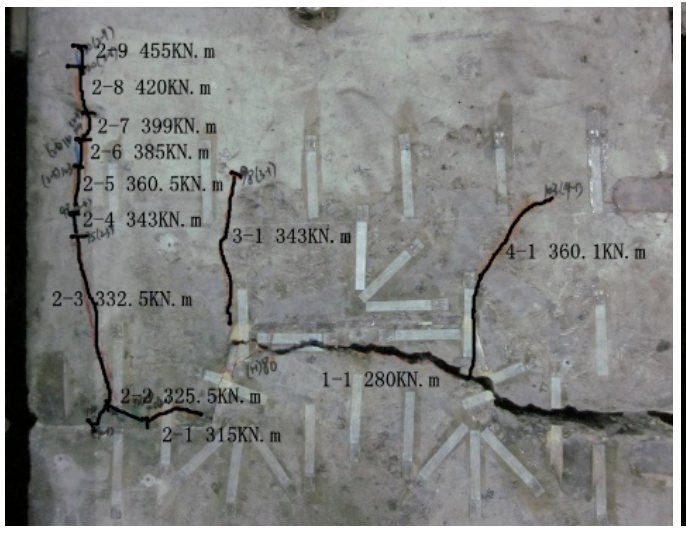

(a) Axial force $1000 \mathrm{kN}$

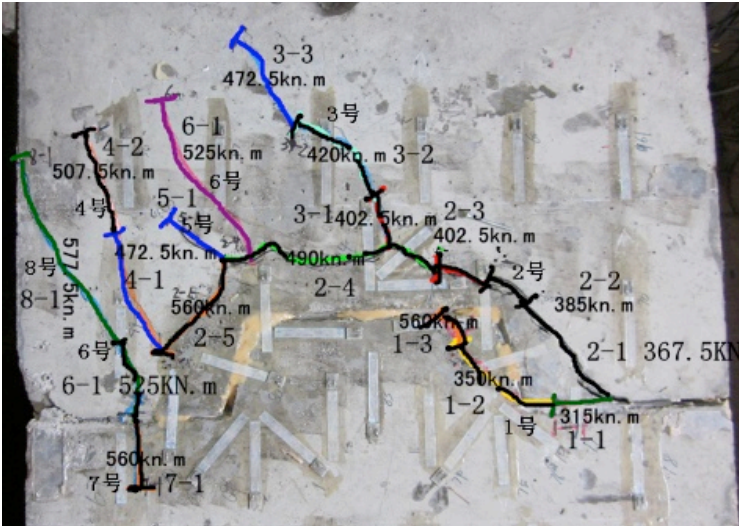

(b) Axial force $2000 \mathrm{kN}$

Fig. (5). Cracks developing under the condition of two axial forces.

Table 3. The key moment under the condition of minimum grouting range of tenon length $95 \mathrm{~mm}$ specimens.

\begin{tabular}{|c|c|c|c|c|c|}
\hline $\begin{array}{c}\text { Axial Force } \\
(\mathbf{k N})\end{array}$ & $\begin{array}{c}\text { Cracks Appearance } \\
\text { (kN.m) }\end{array}$ & $\begin{array}{c}\text { Cracks Extension to the } \\
\text { Top of the Tenon (kN.m) }\end{array}$ & $\begin{array}{c}\text { Cracks Cut-Through } \\
\text { Tenon (kN.m) }\end{array}$ & $\begin{array}{c}\text { Several Parallel Cracks } \\
\text { Appearance in Groove (kN.m) }\end{array}$ & $\begin{array}{c}\text { The Final } \\
\text { Bearing (kN.m) }\end{array}$ \\
\hline \hline 0 & $/$ & $/$ & 140 & 140 & 140 \\
\hline 500 & $/$ & $/$ & 210 & 213.5 & 213.5 \\
\hline 1000 & $/$ & $/$ & 280 & 540 & 350 \\
\hline 1600 & 280 & 350 & 410 & 577 & 665 \\
\hline 2000 & 315 & 385 & 490 & 595 & 56 \\
\hline
\end{tabular}

Table 4. Joint flexural rigidity formula under the condition of grouting epoxy and designing grouting range of tenon length 195 mm specimen.

\begin{tabular}{|c|c|c|c|}
\hline \multirow{3}{*}{ Grouting Material } & Axial Force Condition (kN) & Grouting Range & Flexural Rigidity Test Formula \\
\hline \hline \multirow{2}{*}{ Epoxy } & 0 & Design range & $k_{\theta}=32.78 e^{\frac{389.2-M}{32.78}}$ \\
\cline { 2 - 5 } & 500 & Design range & $k_{\theta}=37.03 e^{\frac{459.3-M}{37.03}}$ \\
\cline { 2 - 4 } & 1000 & Design range & $k_{\theta}=68.04 e^{\frac{794.3-M}{68.04}}$ \\
\cline { 2 - 4 } & \multirow{2}{*}{2000} & Design range & $k_{\theta}=76.43 e^{\frac{879.2-M}{76.43}}$ \\
\cline { 2 - 4 } & & Design range & $k_{\theta}=101.9 e^{\frac{1143-M}{101.9}}$ \\
\hline
\end{tabular}

From Table 4, the flexural rigidity is seen to increase with the increasing axial force but decreases with the increasing moment. According to the test formula, it can be seen that the flexural behavior of $195 \mathrm{~mm}$ tenon joint is superior to the $95 \mathrm{~mm}$ one. It means that the length of the tenon has some influence on the joint flexural rigidity.

\section{CONCLUSION}

Some related literatures $[9,10]$ also describe the shield segment joint test system. But the loading tonnage and the test items cannot be compared to the new system, and the system needs to be considered more thoroughly and more practically. Up to now, the new test system works well and test precision meets the requirements. The test data has offered a good reference for design and is also ready for the subsequent double tenons-grooves test and shear test.

\section{CONFLICT OF INTEREST}

The authors confirm that this article content has no conflict of interest. 


\section{ACKNOWLEDGEMENTS}

Declared none.

\section{REFERENCES}

[1] H. S. Jiang, and X.Y. Hou, "Theoretical study of rotating stiffness of joint in shield tunnel segments," Chinese Journal of Rock Mechanics and Engineering, vol. 23, pp. 1574-1577, 2004.

[2] N. Yu, T.H. Bai, and H.H. Zhu, "Model experimental study on joints stiff of precast and prestressed concrete lining in shield tunnels," Chinese Journal of Underground Space and Engineering, vol. 5, pp. 439-449, 2009.

[3] R. Guo, C. He, K. Feng, and M. Q. Xiao, "Bending stiffness of segment joint and its effects on segment internal force for underwater shield tunnel with large cross-section," China Railway Science, vol. 34, pp. 47-53, 2013.

[4] H.E.I. Naggar, S. D. Hinchberger, and K. Y. Lo, "A closed-form solution for composite tunnel linings in a homogeneous infinite iso- tropic elastic medium," Canadian Geotechnical Journal, vol. 45, pp. 266-287, 2008 .

[5] J.G. Zhang, and C. He. "Model of mechanical behavior with whole segmental lining shield tunnel," Engineering Mechanics, vol. 30, pp. 136-146, 2013.

[6] Z.X. Su, C. He. "Shell-spring-contact model for shield tunnel segmental lining analysis and its application," Engineering Mechanics, vol. 24, pp. 131-136, 2007.

[7] D.Z. Zhao, and L. H. Jing, "Study on flat shell-joint elementfoundation model for segment of shield tunnels," Engineering Mechanics, vol. 28, pp. 110-117, 2011.

[8] J. S. Chen, and H.H. Mo, "Three-dimensional FEM analysis on flexural rigidity of segment joints in shield tunnel," Journal of the China Railway Society, vol. 31, pp. 87-91, 2009.

[9] H.M. Zhan, The Study of the Theory of the Shield Tunnel and Construction Practice, Building Industry Press: CA: China, 2010, pp. 341-349.

[10] M. N. Wang, Z.Y. Li, and L. H. Wei, Tunnel and Underground Railway Precast Technology," Southwest Jiaotong University Press: CA, 2009, pp. 1-26.

(C) Huifeng et al.; Licensee Bentham Open

This is an open access article licensed under the terms of the Creative Commons Attribution Non-Commercial License (http://creativecommons.org/licenses/ by-nc/4.0/) which permits unrestricted, non-commercial use, distribution and reproduction in any medium, provided the work is properly cited. 